\title{
The erroneous eponym of the carotico-clinoid foramen of Henle: attribution is due to Alexander Monro (primus)
}

\author{
Matthew J. Zdilla ${ }^{1,2}$ \\ ${ }^{1}$ Department of Natural Sciences and Mathematics, West Liberty University, West Liberty, WV, USA \\ ${ }^{2}$ Department of Graduate Health Sciences, West Liberty University, West Liberty, WV, USA
}

\begin{abstract}
The carotico-clinoid foramen is an inconsistent anatomical variation created by an osseous bridging between the anterior and middle clinoid processes that encircles the internal carotid artery. Due to its neurosurgical importance, several articles make note of the foramen. When describing the carotico-clinoid foramen, articles attribute its first description to Jakob Henle in 1855 and, likewise, use the eponym carotico-clinoid foramen of Henle. This report presents evidence that Henle was not the first to describe the carotico-clinoid foramen. Rather, the foramen was first described by Alexander Monro (primus) over a century earlier in 1726. Future studies noting the provenance of the carotico-clinoid foramen should attribute its discovery to Monro. Therefore, the eponym carotico-clinoid foramen of Henle should be named the carotico-clinoid foramen of Monro.
\end{abstract}

Keywords: anatomy; caroticoclinoid foramen; terminology

Anatomy 2017;11(2):104-106 @2017 Turkish Society of Anatomy and Clinical Anatomy (TSACA)

The carotico-clinoid foramen $(\mathrm{CCF})$ is an anatomical variation formed by an osseous bridging between the anterior clinoid and middle clinoid processes of the sphenoid. ${ }^{[1,2]}$ When present, the CCF encompasses the internal carotid artery (ICA) ${ }^{[2]}$ Due to this relationship, retraction of the ICA in the presence of a CCF may have life- threatening consequences. ${ }^{[3]}$ Therefore, the carotico-clinoid is frequently noted in neurosurgical literature.

A literature review regarding the CCF reveals numerous manuscripts that either use the eponymous term carotico-clinoid foramen of Henle or otherwise state that the CCF was first described by Henle in $1885^{[1,4-16]}$ However, Henle was not the first to describe the CCF.

Although Henle mentions the foramen carotico-clinoideum in his 1885 text 'Handbuch der systematischen Anatomie des Menschen', Alexander Monro (primus) described the CCF over a century earlier in his 1726 text 'The anatomy of the bumane bones' (Figure 1). ${ }^{[17,18]}$ Monro notes that anterior clinoid processes are frequently joined with the posterior clinoid processes or with the "Body of the Bone itself, by a bony Cross-bridge under which the Carotide Arteries pass" (Figures 2 and 3). ${ }^{[17]}$

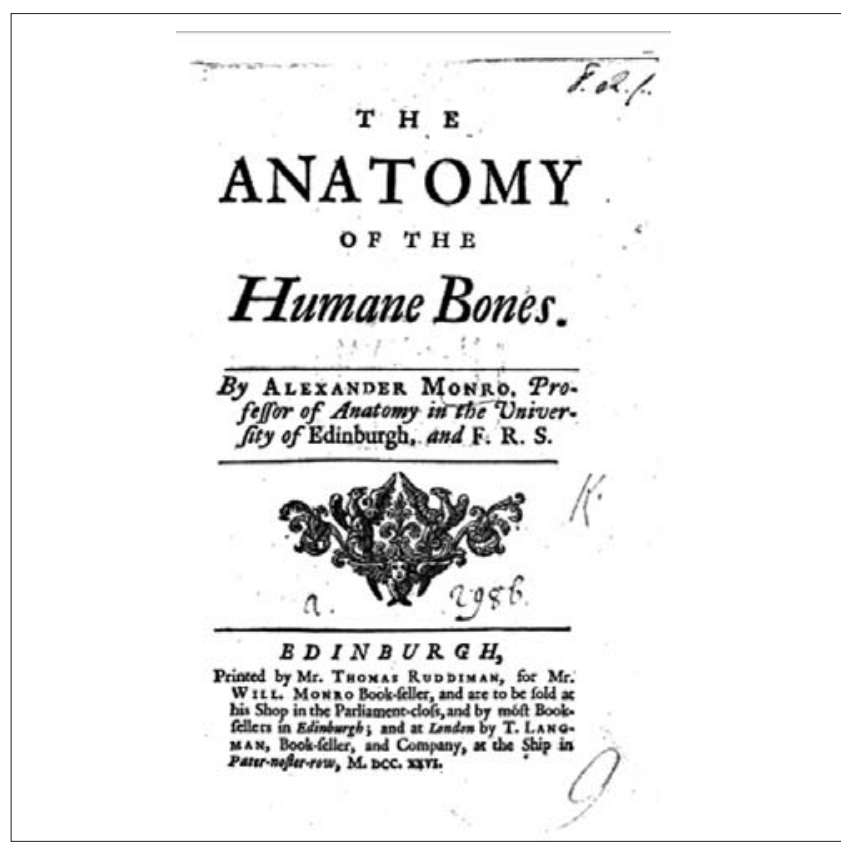

Figure 1. Cover page from the first edition of Alexander Monro's 'The anatomy of the humane bones' published in 1726. 


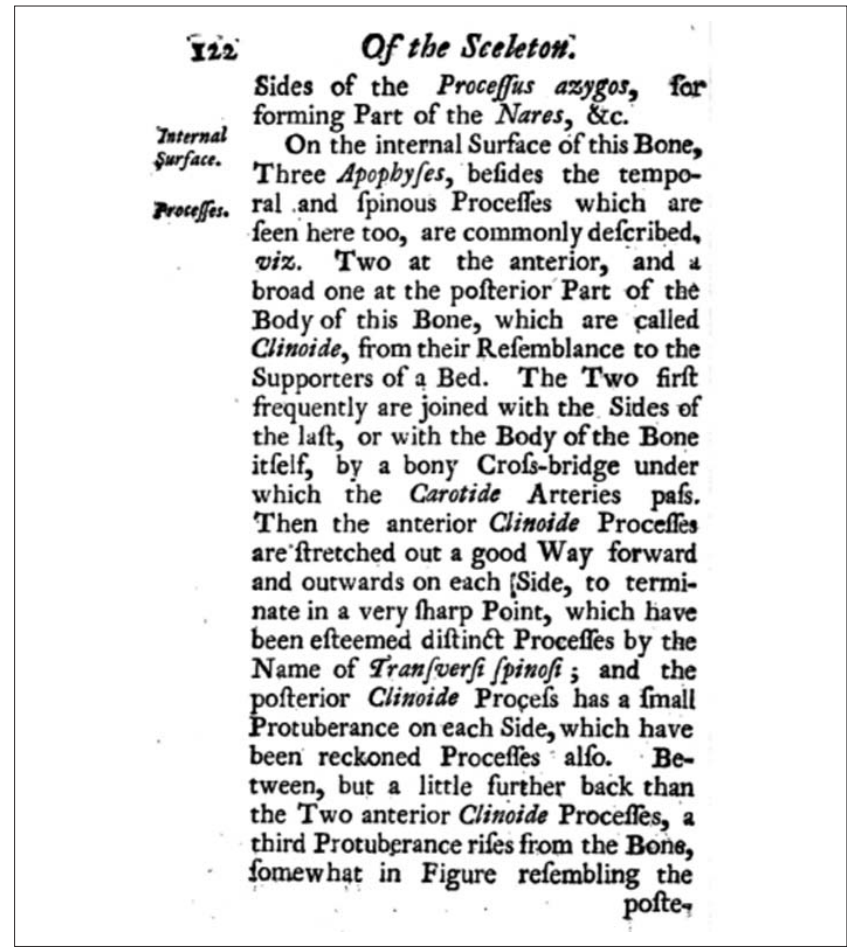

Figure 2. Page 122 of Monro's 1726 text 'The anatomy of the humane bones' which documents the carotico-clinoid foramen and its relationship to the carotid artery.

Furthermore, even Henle's contemporaries described the CCF prior to 1855 in anatomical handbooks including Carl Ernst Bock's 1849 publication 'Handbuch der Anatomie des Menschen' and Joseph Hyrtl's 1850 publication 'Lebrbuch der Anatomie des Menschen, mit Rücksicht auf physiologische Begriindung und praktische Anwendung: Histologie, Knochen-, Bänder- und Muskellebre' (Figures 4 and 5). ${ }^{[1,2,20]}$ Excerpts from the aforementioned texts may be seen in Figure 6. Further, Hyrtl made note of morphological variation of the CCF - specifically, that the middle clinoid

Two at the anterior, and a
broad one at the poiterior Part of the
Body of this Bone, which are called
Clinoide, from their Refemblance to the
Supporters of a Bed. The Two firft
frequently are joined with the Sides of
the laft, or with the Body of the Bone
itfelf, by a bony Crofs-bridge under
which the Carotide Arteries pafs.

Figure 3. Excerpt from page 122 of Monro's 1726 text 'The anatomy of the humane bones', as seen in Figure 2 that has been enlarged and digitally enhanced. The excerpt notes that the two anterior clinoid processes join either the posterior clinoid processes or the body of the bone forming a bony cross-bridges under which the carotid arteries pass.

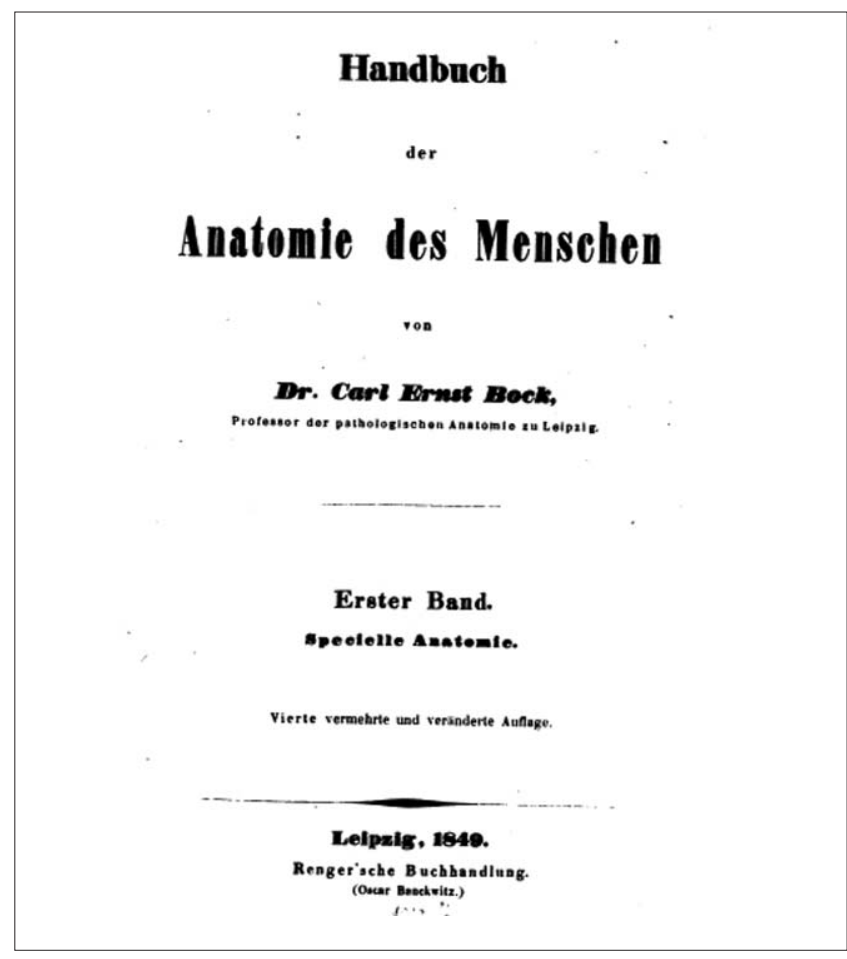

Figure 4. Cover page from Carl Ernst Bock's 'Handbuch der Anatomie des Menschen' published in 1849.

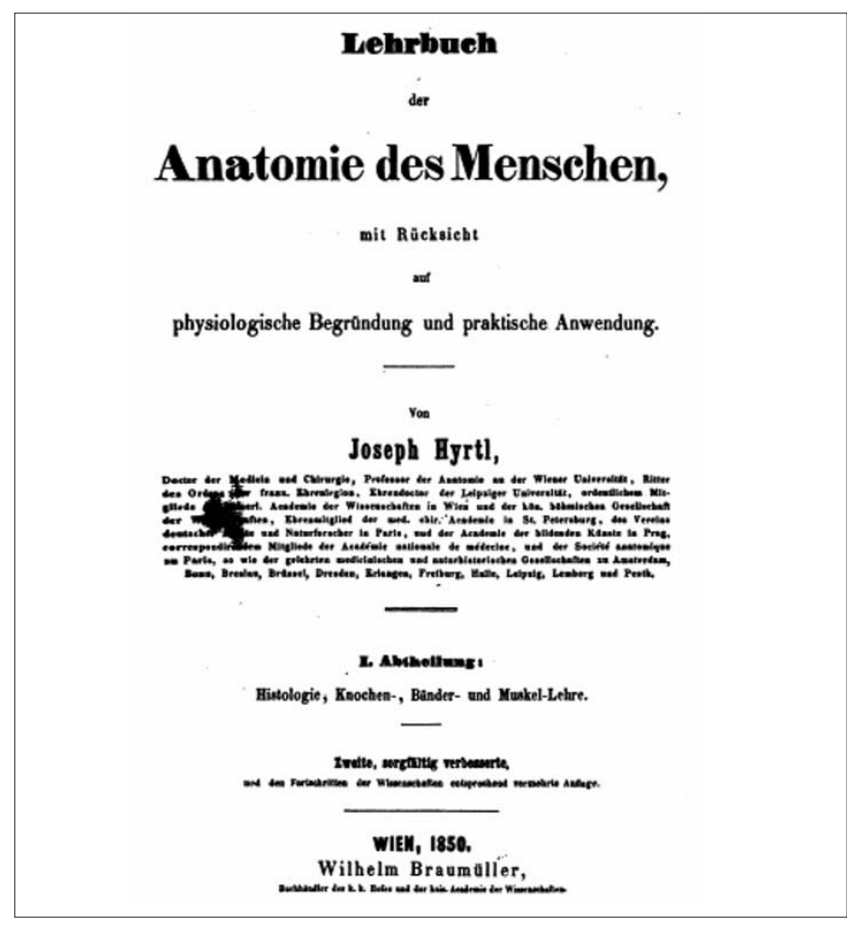

Figure 5. Cover page from Joseph Hyrtl's 'Lehrbuch der Anatomie des Menschen, mit Rücksicht auf physiologische Begründung und praktische Anwendung: Histologie, Knochen-, Bänder- und Muskellehre' published in 1850 . 


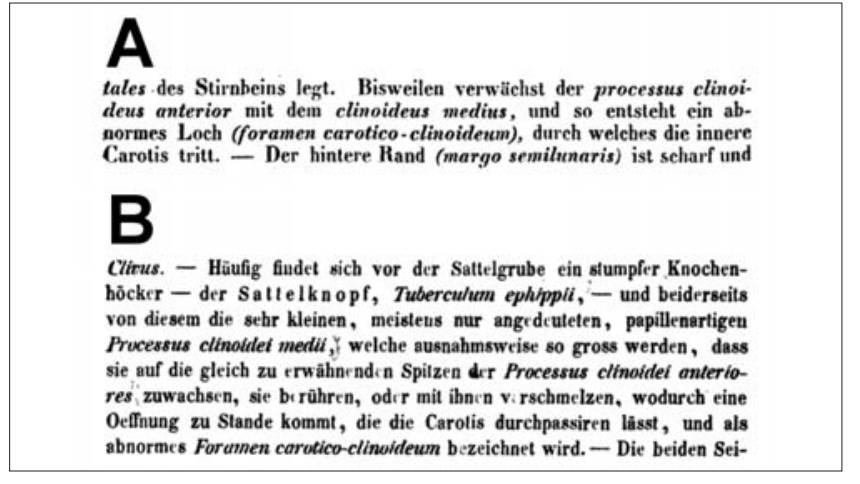

Figure 6. Descriptions of the carotico-clinoid foramen (i.e., foramen carotico-clinoideum) in excerpts from the texts of Carl Ernst Bock's 1849 'Handbuch der Anatomie des Menschen' (A) and Joseph Hyrtl's 1850 'Lehrbuch der Anatomie des Menschen, mit Rücksicht auf physiologische Begründung und praktische Anwendung: Histologie, Knochen-, Bänder- und Muskellehre' (B).

process could extend toward, touch, or fuse with the anterior clinoid (Figure 6). ${ }^{[20]}$

In conclusion, this article provides evidence that the provenance of the carotico-clinoid foramen heretofore ascribed to Henle is ill-suited. Indeed, the CCF was described in 1726 by Alexander Monro (primus)- predating Henle's description by more than a century. Therefore, with regard to the eponym, the carotico-clinoid foramen of Henle should be renamed the carotico-clinoid foramen of Monro.

\section{References}

1. Lang J. Structure and postnatal organization of heretofore uninvestigated and infrequent ossifications of the sella turcica region. Acta Anat 1977;99:121-39.

2. Zdilla MJ, Cyrus LM, Lambert HW. Carotico-clinoid foramina and a double optic canal: a case report with neurosurgical implications. Surg Neurol Int 2015;6:13.

3. Lee HY, Chung IH, Choi BY, Lee KS. Anterior clinoid process and optic strut in Koreans. Yonsei Med J 1997;38:151-4.

4. Erturk M, Kayalioglu G, Govsa F. Anatomy of the clinoidal region with special emphasis on the caroticoclinoid foramen and interclinoid osseous bridge in a recent Turkish population. Neurosurg Rev 2004:27:22-6.
5. Desai SD, Sreepadma S. Study of carotico clinoid foramen in dry human skulls of north interior Karnataka. National Journal of Basic Medical Sciences 2010;1:60-4.

6. Kapur E, Mehiç A. Anatomical variations and morphometric study of the optic strut and the anterior clinoid process. Bosn J Basic Med Sci 2012;12:88-93.

7. Shaikh SI, Ukey RK, Kawale DN, Diwan CV. Study of carotico-clinoid foramen in dry human skulls of Aurangabad district. Iran J Basic Med Sci 2012;3:148-54.

8. Archana BJ, Shivaleela C, Kumar GV, Pradeep P, Lakshmiprabha S. An Osteological study of incidence, morphometry and clinical correlations of carotico-clinoid foramen in dried adult human skulls. Research Journal of Pharmaceutical, Biological and Chemical Sciences 2013;4: $347-52$.

9. Hasan T. Bilateral caroticoclinoid and absent mental foramen: rare variations of cranial base and lower jaw. Ital J Anat Embryol 2013;118: 288-97.

10. Yadav Y, Nayeemuddin SM, Chakradhar V, Goswami P. Ossification of caroticoclinoid ligament and its clinical importance. Int J Biomed Res 2014;5:294-5.

11. Brahmbhatt RJ, Bansal M, Mehta C, Chauhan KB. Prevalence and dimensions of complete sella turcica bridges and Its clinical significance. Indian J Surg 2015;77:299-301.

12. Gupta N, Rai AL. Anatomical variations of anterior clinoid process with its surgical importance. Innovative Journal of Medical and Health Science 2015;5:28-30.

13. Mallik S, Sawant VG. Bilateral "Carotico-clinoid Foramen" with "Sella Turcica Bridge"-a case report. Anat Physiol 2015;5:S5.

14. Ota N, Tanikawa R, Miyazaki T, Miyata S, Oda J, Noda K, Tsuboi T, Takeda R, Kamiyama H, Tokuda S. Surgical microanatomy of the anterior clinoid process for paraclinoid aneurysm surgery and efficient modification of extradural anterior clinoidectomy. World Neurosurg 2015;83:635-43.

15. Bilodi A, Kumar S, Karthikeyan V. Study of inconsistent structure in the anterior cranial fossa of an Indian human skull. World Journal of Pharmacy and Pharmaceutical Sciences 2016;5:1671-7.

16. Jha S, Singh S, Bansal R, Chauhan P, Shah MP, Shah A. Nonmetric analysis of caroticoclinoid foramen in foothills of Himalayas: its clinicoanatomic perspective. Morphologie 2017;101:47-51.

17. Monro A. The anatomy of the human bones. Edinburgh: Thomas Ruddiman; 1726. p. 122.

18. Henle J. Handbuch der systematischen Anatomie des Menschen. Braunschweig: Druck und Verlag von Friedrich Vieweg und Sohn; 1855. p. 99.

19. Bock CE. Handbuch der Anatomie des Menschen. Vol 1. Leipzig: Oscar Banckwitz; 1849. p. 42.

20. Hyrtl J. Lehrbuch der Anatomie des Menschen, mit Rücksicht auf physiologische Begründung und praktische Anwendung: Histologie, Knochen-, Bänder- und Muskellehre. Wein: Wilhelm Braumüller; 1850. p. 180 .

Correspondence to: Matthew J. Zdilla, D.C.

Department of Natural Sciences and Mathematics, West Liberty University, CSC 139; P.O. Box 295, 26074, West Liberty, WV, USA

Phone: +1 3043368631

e-mail: mzdilla@westliberty.edu

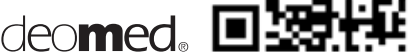

Conflict of interest statement: No conflicts declared.

This is an open access article distributed under the terms of the Creative Commons Attribution-NonCommercial-NoDerivs 3.0 Unported (CC BY-NCND3.0) Licence (http://creativecommons.org/licenses/by-nc-nd/3.0/) which permits unrestricted noncommercial use, distribution, and reproduction in any medium, provided the original work is properly cited. Please cite this article as: Zdilla MJ. The erroneous eponym of the carotico-clinoid foramen of Henle: attribution is due to Alexander Monro (primus). Anatomy 2017;11(2):104-106. 